\title{
A NEW SPECIES OF CADDISFLY (TRICHOPTERA: LEPIDOSTOMATIDAE: LEPIDOSTOMA) FROM TAMIL NADU, INDIA
}

\author{
S. Dinakaran ${ }^{1}$, S. Anbalagan ${ }^{2} \&$ C. Balachandran ${ }^{3}$ \\ 1,2,3 Centre for Research in Aquatic Entomology, The Madura College, Madurai, Tamil Nadu 625011, India \\ ${ }^{1}$ dinkarji@gmail.com (corresponding author), ${ }^{2}$ anbumdu@gmail.com, ${ }^{3}$ bchandruji@gmail.com
}

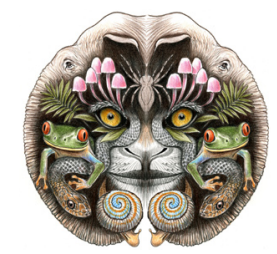

ISSN

Online 0974-7907

Print 0974-7893

OPEN ACCESS
Abstract: Lepidostoma nuburagangai, a new species (Trichoptera: Lepidostomatidae), was collected from Nuburagangai Stream of Alagar Hills, Tamil Nadu, India. The adult male and female, pupa, larva and case are described. The species is found in the deposits of dead plant material in slow-moving streams.

Keywords: Alagar Hills, caddisfly, Lepidostoma, new description, southern India.

In the course of our project on gene banking and habitat inventory of southern Indian caddisflies, we identified the genus Lepidostoma with larval morphology and ecology, since they are partially accountable for leaf litter decomposition. A few species of this family have been recorded in southern Indian streams such as Lepidostoma fuscatum (Navas, 1932), L. inaequale (Martynov, 1936), L. khasianum (Mosely, 1949) and L. palnicum (Mosely, 1949) and the consolidated details of their distribution has been provided by the family Lepidostomatidae which is distributed throughout the streams of southern India (Dinakaran \& Anbalagan 2007, 2010; Anbalagan et al. 2012), but there has been little attention paid to taxonomic studies of this family in India. During a routine survey, specimens of Lepidostomatidae were collected from the streams of Alagar Hills. Among them, a new species has been observed and the present article describes this species based on the following features: adult, male, female, larvae and pupa.

\section{Study area}

Alagar Hills: The reserve forests of Alagar Hills $\left(10^{\circ} 14^{\prime} 180^{\prime \prime} \mathrm{N} \& 77^{0} 58^{\prime} 567^{\prime \prime} \mathrm{E}\right)$ lie $22 \mathrm{~km}$ northeast of Madurai City. These hill ranges are important pilgrimage sites with seasonal springs (Garudatheertham 350m) and perennial springs like Nuburagangai (425). In the present study, the specimens were collected from Nuburagangai Stream. The maximum and minimum temperatures were $41-29{ }^{\circ} \mathrm{C}$ respectively during summer and $29-22$ ${ }^{\circ} \mathrm{C}$ in December. The whole reserve forest area receives erratic rainfall most of which comes from the retreating northeast monsoon and a little during the southwest monsoon.

\section{Material and Methods}

The collection, rearing and description procedures were identical to Blahnik \& Holzenthal (2004) and Holzenthal \& Andersen (2004). Terminology for genitalia and wing venation description are according to Ito (2001). The type material is deposited in the collections of the Centre for Research in Aquatic Entomology (CRE) (Gene bank accession no. E0070), The Madura College, Madurai, Tamil Nadu, India.

\footnotetext{
DOI: http://dx.doi.org/10.11609/JoTT.02116.790 | ZooBank: urn:Isid:zoobank.org:pub:15289A10-EC65-4B6A-85B2-A832D9E4A437

Citation: Dinakaran, S., S. Anbalagan \& C. Balachandran (2013). A new species of caddisfly (Trichoptera: Lepidostomatidae: Lepidostoma) from Tamil Nadu, India. Journal of Threatened Taxa 5(1): 3531-3535; doi:10.11609/JoTT.o2116.790

Copyright: @ Dinakaran et al. 2013. Creative Commons Attribution 3.0 Unported License. JoTT allows unrestricted use of this article in any medium, reproduction and distribution by providing adequate credit to the authors and the source of publication.

Funding: This study is part of the University Grants Commission's funded major project (F.No. 31-216/2005 SR).

Competing Interest: None.
}

Acknowledgements: We are grateful to Prof. John C. Morse, Clemson University, Clemson, USA, Dr. Tomiko Ito, Hokkaido Fish Hatchery, Kita-kashiwagi, Eniwa, Hokkaido-061-1433, Japan and Dr. John Weaver, Department of Entomology, University of New Hampshire, Durham, USA for help and support for this study. 


\section{Lepidostoma nuburagangai sp. nov.}

Dinakaran \& Anbalagan (Figs. 1-5)

urn:Isid:zoobank.org:act:40EE186E-F432-41DF-A54D-332D5C3C7FB5

\section{Specimens examined}

Holotype: Male, 15.ix.2007, Nuburagangai Stream, Tamil Nadu, India (10 $\left.14^{\prime} 180^{\prime \prime} \mathrm{N} \& 7^{\circ} 58^{\prime} 567^{\prime \prime} \mathrm{E}, 425 \mathrm{~m}\right)$, coll. S. Anbalagan \& C. Balachandran, deposited in the CRE (E0076). Allotype (adult female): same data as holotype; deposited in the CRE (E0071). Paratypes: 18 male adults, six female adults, five female pupae, 52 larvae, Nuburagangai stream $\left(10^{\circ} 14^{\prime} 180^{\prime \prime} \mathrm{N}\right.$ \& $77^{0} 58^{\prime} 567^{\prime \prime} \mathrm{E}, 425 \mathrm{~m}$ ); 12.xii.2006 (deposited in the CRE E0068), 10 male adults, two female adults, two female pupae and 47 larvae, same locality, date and collectors as holotype; deposited in the CRE Caddisfly Gene bank, Accession number: E0070, 10 male adults, two female adults, 64 larvae (Gene bank, CRE); 25.xii.2006, Thadaganachiamman Stream, (8057'.938' $\mathrm{N}$ \& $77^{\circ} 08^{\prime} .73^{\prime \prime} \mathrm{E}, 375 \mathrm{~m}$ ) coll. S. Dinakaran \& S. Anbalagan.

\section{Descriptions}

Holotype (adult male in alcohol): Yellow, $5.0-5.5 \mathrm{~mm}$ long, Antennae 7.0-8.0 mm long. Scape, 0.99mm long, cylindrical, densely covered with numerous setae and scales (Fig. 1A). Maxillary palpi thick, each 2-segmented, $0.69 \mathrm{~mm}$ long and densely covered with scales, relative lengths of two segments from base to apex 1:5. Labial palpi each 3-segmented, $1.1 \mathrm{~mm}$ long, relative lengths of three segments from base to apex 1:1.5:2; both pairs of palpi covered with fine setae (Fig. 1A). Forewings, each $6-7 \mathrm{~mm}$ long, $2.5 \mathrm{~mm}$ wide (Fig. 1B). Hind wings, $4.5-5.0 \mathrm{~mm}$ long, $2.3 \mathrm{~mm}$ wide (Fig. $1 \mathrm{C}$ ). Fore- and hind wing venation as in Fig. 1B closed discoidal and opened thyridial cells present in fore- and hind wings. Genitalia with tergum $X$ consisting of mesal arms and lateral arms and membranous lobe (Fig. 1D); mesal arms completely fused medially, apex bluntly triangular with thick setae (Fig. 1E); lateral arms directed ventrocaudally at basal half, apex triangular with three setae (Figs. 1D, E). Membranous lobe directed ventrocaudally and round apically. Phallus, membranous, slender at basal half, slightly expanded distally (Fig. 1F). Inferior appendages each with main article thick at base and gradually tapered to apical row of five setae; its harpago tall and hatchet-shaped; its dorsal hook somewhat triangular and inferior hook bud-like and $1 / 2$ as long as basal width of main article. Inner hook short and smaller than basal width of main article. Superior harpage arising on base of main body of inferior appendage, slender and elongated laterally (Fig. 1D).
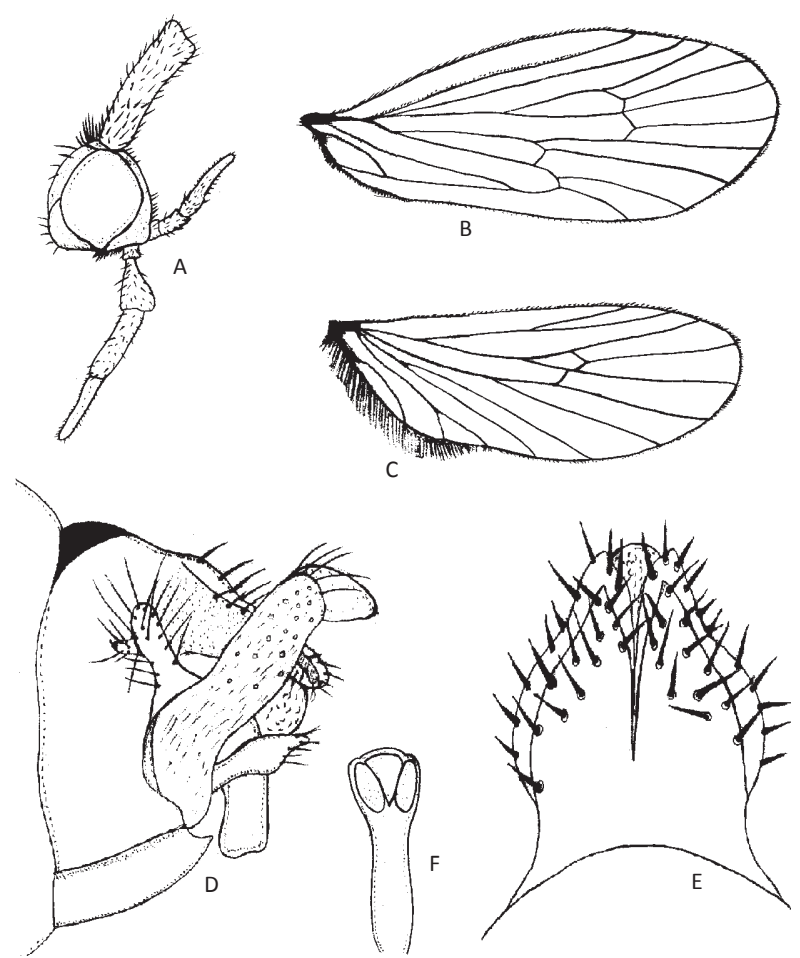

Figure 1. Lepidostoma nuburagangai sp. nov. (male). A - Head, scape and mouth parts, right lateral; B - right fore wing, dorsal; C - right hind wing, dorsal; D - abdominal segments VIII$\mathrm{X}$, left lateral; E - abdominal segments VIII- X, dorsal; $\mathrm{f}$ - phallus, ventral.

Allotype (adult female in alcohol): Yellowish-brown, 5.0-6.0 mm long. Antennae each 7-8 mm long. Scapes each $1.0 \mathrm{~mm}$ long. Maxillary palpi each 5 -segmented and $0.92 \mathrm{~mm}$ long, relative lengths of 5 -segments from base to apex, 1:1.5:1.5:2:2.5. Labial palpi each 3-segmented, $0.7 \mathrm{~mm}$ long, relative lengths of 3-segments from base to apex 1:1:1.5, both pairs of palpi covered with fine setae (Fig. 2A). Forewings each $6.5-7 \mathrm{~mm}$ long (Fig. $2 B$ ), hind wings each 5.5-6.0 mm long, fore and hind wing venation as in Figs. 2B,C. Closed discoidal and opened thyridial cells present in fore and hind wings. Posterolateral margins of tergum VIII with posterolateral corners rectilinear; anterolateral corners rectanglular rounded (Fig. 2D). Lateral plate short, pentagonal and strongly sclerotized. Subgenitial plate heavily sclerotized, trapezoidal, with acute posteromedial and lateromedial projections (Fig. 2E). Tergite IX separated from tergite $X$ by membrane. Vaginal apparatus diamond-shaped with lateral projections on posterolateral corners, anterior half of vaginal apparatus tongue-like and weakly sclerotized (Fig. 2F).

Pupa (female in alcohol): Length $6 \mathrm{~mm}$. Antennae slightly greater than body length and longer than male antennae. Labrum with five pairs of long setae on 

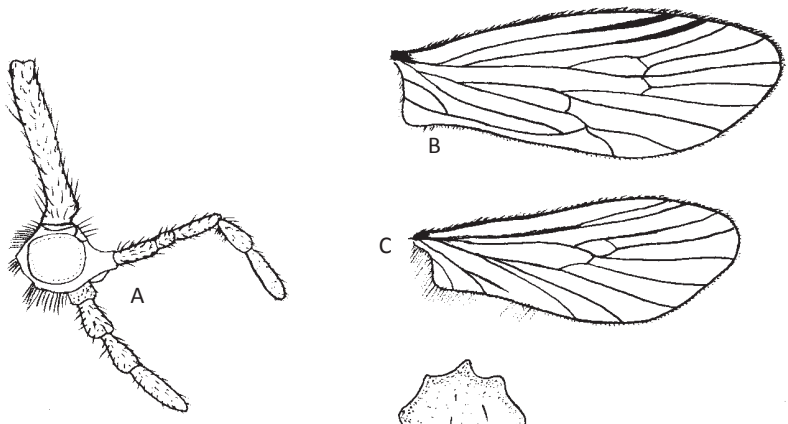

C
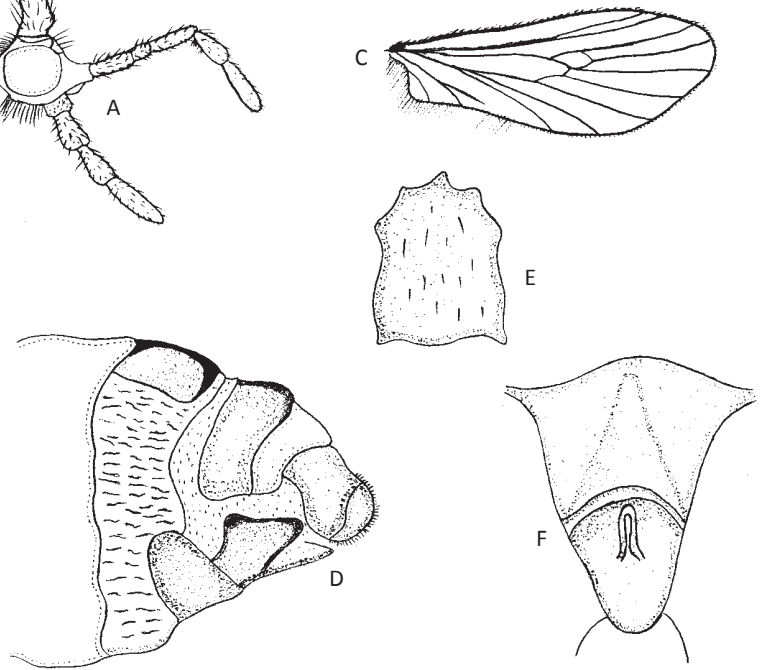

Figure 2. Lepidostoma nuburagangai sp. nov. (female) A - Head, scape and mouthparts, right lateral; B - right fore wing, dorsal; C - right hind wing, dorsal; D - abdominal segments of VIII-X, left lateral; E - subgenital plate, ventral; F - vaginal apparatus, ventral.

dorsum, each seta hooked apically (Fig. 3A). Mandibles heavily sclerotized, each thick at base and acute at apex, mesal margin slightly concave, serrate, with numerous very fine sharp teeth on blade (Fig. 3B). Mesotarsi each with dense fringe of setae (Fig. 3C). Abdominal segment I with pair of spined ridges (Fig. 3D). Single ventrolateral gills present on segments II and III (posterior), VII and VIII (anterior) and IV to VI (anterior and posterior). Lateral fringe extending along sides of anterior part of III and along full lengths of VII and VIII. Pairs of hook plates on the bases of segments III-VI elliptical with hooks curved backward, hook numbers and shape varying among individuals and according to body size (Fig. 3E). Segments I-VIII each with pair of short dorsal setae (Fig. 3D). Segment VII and VIII each bearing thick row of lateral brushes of setae. Pair of triangular anal processes broad basally, depressed and apically angulate, each with five long setae at apex and many short setae on dorsal and ventral surfaces.

Final instar larva (in alcohol): Head width and body length of final instar larva up to $0.53 \mathrm{~mm}$ and $8-9 \mathrm{~mm}$ respectively. Head, brown with many round light spots (muscle scars) at posterior half. Primary setae 4, 5, 9 and 10 black; setae $1,2,3,6,7,8$ and 11 transparent; setae 2, 9, 10 and 11 very short (Fig. 4A). Ventral apotome vase-like, $2 \mathrm{x}$ as long as posterior ecdysial
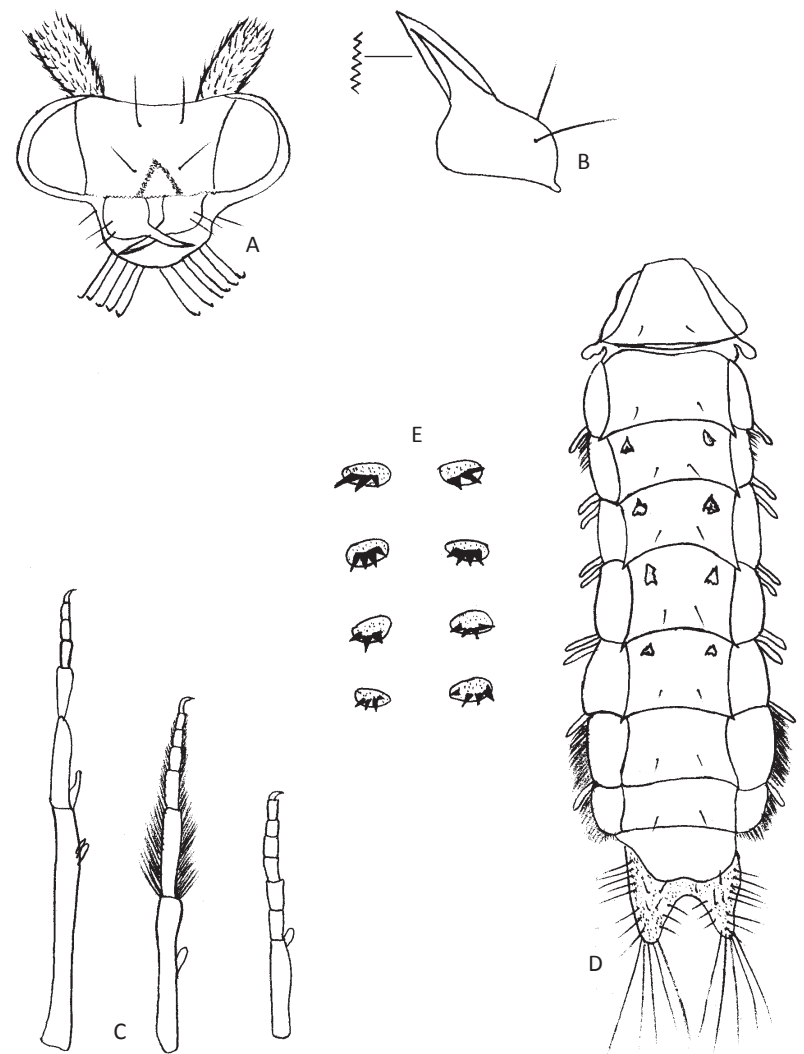

Figure 3. Pupa of Lepidostoma nuburagangai sp. nov. A - Head of female, frontal; B - right mandible, dorsal; C - from right to left, left protarsus, left mesotarsus and left metatarsus, posterior; D - abdominal segments, dorsal. E - anterior hook plates of abdominal segments III-VI.

line separating genae; cardines transversely long, each cardo with mesal apex thickened (Fig. 4B). Mandibles sclerotized, triangular in dorsal view, each with three teeth at apex and two brushes of setae present on basal half of mesodorsal blade, posterior brush twice as long as anterior brush (Fig. 4C). Labrum wide with membranous anterior and lateral margins; setae 1 and 2 blunt and transparent spine-like, situated on membrane; setae 3, 4, 5 and 6 dark brown (Fig. 4D). Antennae each situated just anterior of periocular spot, short, twice as long as basal width and not segmented. Pronotum sclerotized dorsally, concolorous with head, bearing 8 pairs of setae on anterior margin; mid-dorsal ecdysial line clear; anterolateral corners rectangular, posterolateral corners triangular (Fig. 5A). Mesonotum separated into two dorsolateral plates by very narrow dorsomedian membranous ecdysial line, anterolateral corners and posterolateral corners rounded. One seta on each sa 1,5 setae on each sa 2 and 7-8 setae on each sa 3. Metanotal area broadly membranous, slightly sclerotized at the bases of setae in setal areas, 1 seta on 


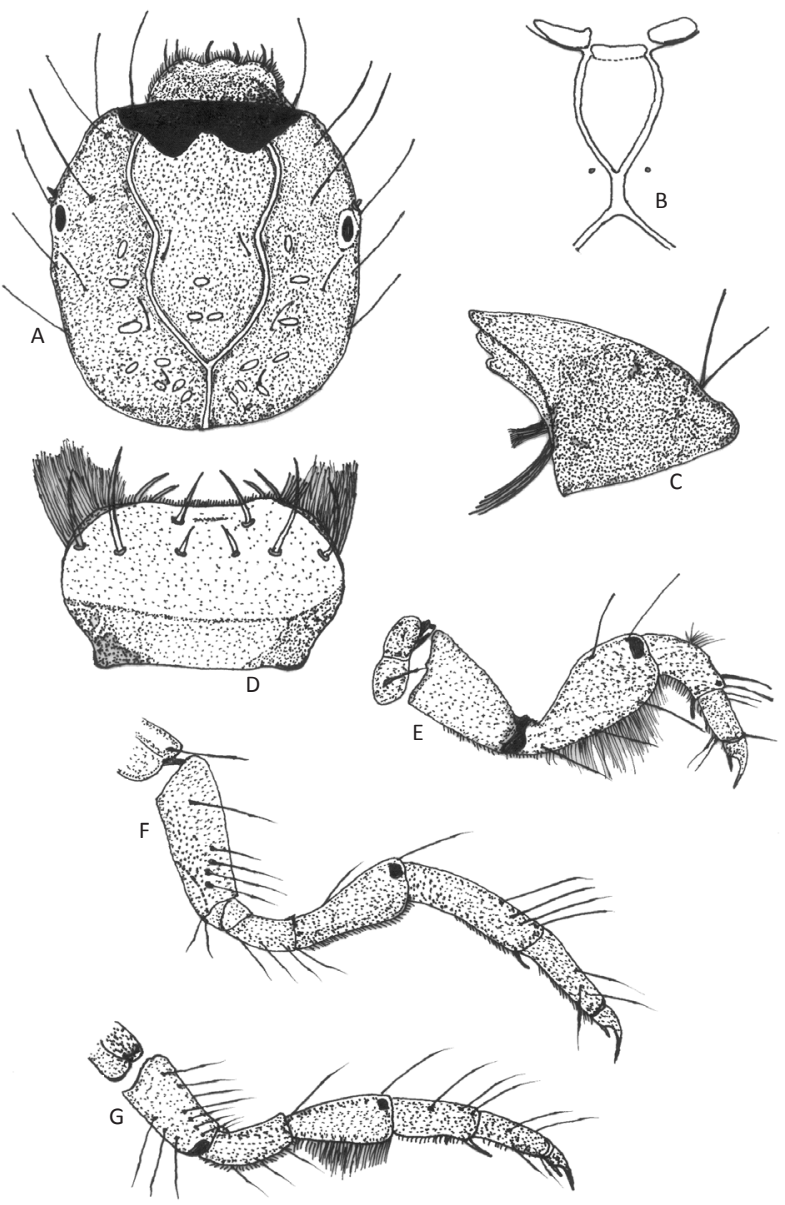

Figure 4. Larva of Lepidostoma nuburagangai sp. nov. A - Head, dorsal; B - ventral apotome, ventral; C - right mandible, dorsal; D - labrum, dorsal; E - right foreleg, posterior; F - right middle leg, posterior; G - right hind leg, posterior.

each sa 1 and sa 2 and $5-6$ setae on each sa 3 . Thoracic legs, light brown, with small dark spot near posterior apicodorsal corner of each femur. Foreleg, shortest (Fig. 4E) and middle leg longest (Fig. 4F). Trochanterofemoral brushes of fore, and hind legs consisting of numerous comb-like setae (Fig. 4G). Numerous spinules covering mesal surfaces of forecoxae and anterobasal areas of hind coxae. Abdominal segments with lateral tubercules present on sides of segment I, each with two long setae and numerous pectinate spines. Lateral fringe and forked lamellae in longitudinal row on each side of segments III-VII (Fig. 5D). Single tracheal gills present subventrally and subdorsally on segments IIVII; segment VIII with broad lobe at each side. Segment IX,short, wide dorsal sclerite with two pairs of long setae and two pairs of short setae on apical margin (Fig. 5B). Anal legs each with anal claw, each anal claw bearing one accessory hook (Fig. 5C).

Larval cases: Length of 4-sided case up to $7-8 \mathrm{~mm}$.
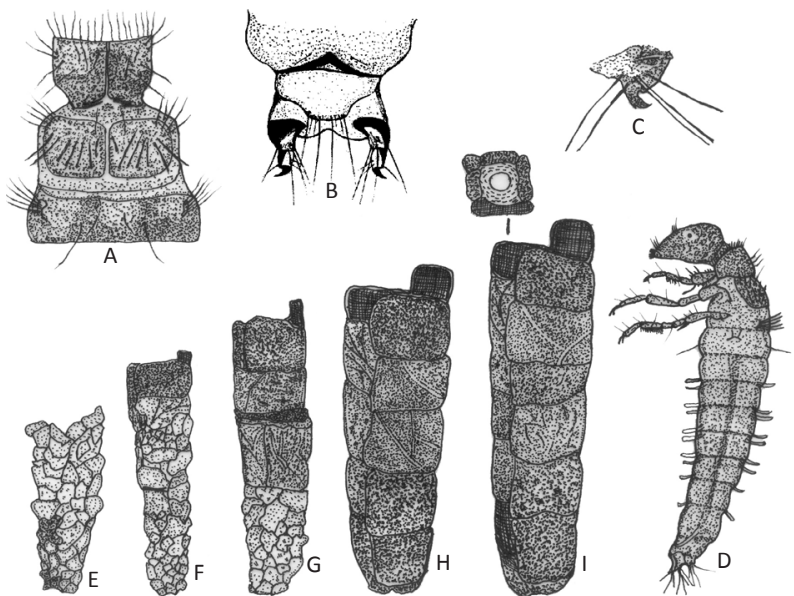

Figure 5. Larva of Lepidostoma nuburagangai sp. nov.

A - thorax, dorsal; B - abdominal segment IX, dorsal; C - left anal claw, left lateral; D - body, left lateral; E - case of first instar (anterolateral); F - case of second instar (anterolateral); G - case of third instar (anterolateral); $\mathrm{H}$ - case of fourth instar (anterolateral); I - case of final instar (anterolateral).

Cylindrical, sand case built by earlier instars and 4-sided leaf-piece case built at $5^{\text {th }}$ instar; posterior end with round opening (Figs. 5E-I).

\section{Etymology}

The new species is named after the stream, Nuburagangai located at Alagar Hills, Tamil Nadu, southern India.

\section{Habitat and Biology}

Gut contents of larvae $(n=25)$ showed the presence of fragments of partially decomposed leaf litter and woody debris. Larvae were found in slow-moving streams where leaf litter and woody debris were deposited. Abundant larvae were found in leaf litter in riffle areas than in leaf litter in pools. Larvae were abundant during early summer (March \& April) and spring (June to August). Physico-chemical characteristics of the collection sites were: stream width $1.9 \pm 0.51 \mathrm{~m}$, depth $5 \pm 2 \mathrm{~cm}$, stream flow $8 \pm 2 \mathrm{~ms}^{-1}$, temperature $26 \pm 2.08{ }^{\circ} \mathrm{C}, \mathrm{pH} 6.9 \pm 0.06$, dissolved oxygen $16.2 \pm 1.1 \mathrm{mgL}^{-1}$.

\section{Diagnosis}

Lepidostoma nuburagangaisp. nov. closely resembles L. palnia (Mosely, 1949) but can be distinguished by the following combination of characters: In the adult male of Lepidostoma nuburagangai sp. nov., maxillary and labial papli characters, wing venation, each inferior appendage has a hatchet-shaped harpago at its apex, inner hook short and smaller than basal width of main article, and the lateral arms of tergum $X$ each has its apex more 
rounded than those of the adult male of L. palnia.

\section{REFERENCES}

Anbalagan, S., S. Dinakaran \& M. Krishnan (2012). Spatio-temporal dynamics of leaf litter associated macroinvertebrates in streams of peninsular India. Ecologia 2(1): 1-11.

Blahnik, R.J. \& R.W. Holzenthal (2004). Collection and curation of Trichoptera, with an emphasis on pinned material. Nectopsyche, Neotropical Trichoptera Newsletter 1: 8-20. Available from http:// www.entomology.umn.edu/museum/links/news.html (Accessed on 28 June 2004)

Dinakaran, S. \& S. Anbalagan (2007). Modern trends for assessment of forest streams and rivers of southern Western Ghats using caddisflies. Bioscan 2(2): 109-112.
Dinakaran, S. \& S. Anbalagan (2010). Spatio-temporal dynamics of caddisflies in streams of southern Western Ghats. Journal of Insect Science 10(46): 1-15

Holzenthal, R.W. \& T. Andersen (2004). The caddisfly genus Triaenodes in the Neotropics (Trichoptera: Leptoceridae). Zootaxa 511: 1-80.

Ito, T. (2001). Description of the type species of the genus Goerodes and generic assignment of three East Asian species (Trichoptera: Lepidostomatidae). Limnology 2: 1-9.

Martynov, A.V. (1936). On a collection of Trichoptera from the Indian Museum. Part II. Integripalpia. Records of Indian Museum, Calcutta 38(3): 239-306

Mosely, M.E. (1949). The Indian caddisflies. Journal of the Bombay Natural History Society 48(4): 782-791+pls. I-XII.

Navas, L. (1932). Decadas de insectos nuevos. Broteria Serie Ciencia Naturale 1: 145-155. 